Cynthia Lee*

\title{
Understanding refusal style and pragmatic competence of teenage Cantonese English learners in refusals: An exploratory study
}

DOI 10.1515/ip-2016-0010

\begin{abstract}
The paper investigates the refusal style of teenage Cantonese learners of English in terms of strategy use, pattern, order, and content of refusals' semantic formulae quantitatively and qualitatively, and discusses learners' pragmatic competence and refusal style with reference to that of adult native Mandarin Chinese (L1) speakers and Chinese English learners reported in the literature. One hundred fifty-six Cantonese English learners aged between 14 and 18, studying in Form 2, Form 4, and Form 6, participated in the study. Refusals to requests were collected using five closed role plays in which sociolinguistic variables were controlled. It was found that three indirect refusal patterns were generally used by the three age groups across situations, with the strategy of giving a specific reason being dominant. Only the difference in use of single strategy was statistically significant $(p<0.05)$. The frequency rate of refusing directly decreased when age and language-learning exposure increased. The older teenage learners refused more indirectly than the young ones. The indirect-with-specific-reason refusal style for requests is consistent with the indirect Chinese communication style of adult native Chinese speakers and Chinese English learners. In addition, the direct-then-indirect development in L2 refusals is similar to that in L2 requests and complaints expressed by young Cantonese English learners, and there are some signs of L1 pragmatic transfer. Teenage learners were able to show sociopragmatic competence by using different refusal strategies in face of different request natures and relationships with interlocutors. However, their pramalinguistic resources were limited, and adjuncts did not exist.
\end{abstract}

Keywords: L2 refusal, Cantonese, teenage learners, pragmatic competence

*Corresponding author: Cynthia Lee, Centre for applied English Studies, The University of Hong Kong, E-mail: cfklee@hku.hk 


\section{Introduction}

In daily communication, we do not always perform what is asked of us. Refusal is not always an avoidable response though it threatens both the speaker's and the hearer's face, particularly in the Chinese culture, in which 面子 (miànzi 'face') is emphasized (Lee-Wong 2000). Face in the Chinese culture takes into account insider and outsider relationships (Bond and Kwang-Kuo 1986; Li and Li 1996) and is treated as an interdependent phenomenon (Pan 2000). However, a speaker can choose to carry out a face-threatening act with or without any redressive action (Brown and Levinson 1987). Similarly, refusal in Chinese can be expressed indirectly or directly through idioms such as 謝絕 (xièjué 'refusing an offer with gratitude'), 婉言謝絕 (wănyán xiè jué 'refusing with gentle/mild words'), 一口拒絕 (yīkǒu huìjué 'refusing rudely or flatly'), and 斷然謝絕 (duànrán jùjué 'refusing absolutely without hesitation') (Chen et al. 1995: 121122). Whatever the speaker chooses and regardless of the culture and the semantic formula, a refusal indicates a negative evaluation of the speaker on the part of the interlocutor. The literature on refusals consists of two main types of empirical studies: L1 refusals expressed by native speakers of different languages, and comparisons of L1 and L2 refusals as expressed by native speakers of the target language and second/foreign (L2) language learners. Data are usually collected through a discourse completion test (DCT) or via role play. Adult native speakers of some languages, such as Chinese (Guo 2012; Li 2007; Wang 2001; Yang 2008) and Malay (Satter et al. 2011), prefer indirect refusals, an inclination that is attributable to the indirect communication style prevalent in their cultures. Comparisons of L1 and L2 refusals as responses to requests, offers, invitations, and suggestions made by some adult native speakers and language learners, such as learners of Greek (Bella 2011 and Bella 2014), learners of Spanish (Félix-Brasdefer 2006), and learners of English (e.g., Allami and Naeimi 2011; Bardovi-Harlig and Hartford 1993; Beebe et al. 1990; Chang 2009 and Chang 2011; Liao and Bresnahan 1996), provide evidence for varied degrees of L1 pragmatic transfer in L2 refusals due to the learner's proficiency level and length of residence in the target community. Unlike requests that have been well researched in terms of semantic formulae from cross-cultural and crosslinguistic perspectives (e.g., Economidou-Kogetsidis 2011; Ellis 1992; Fukushima 1996; Hassall 2003; Lee 2004, Lee 2005, Lee 2011; Rinnert and Kobayashi 1999) and L2 developmental patterns from childhood through the teens (Achiba 2003; Rose 2000, Rose 2009), refusals produced by other age groups and the ways in which their refusals' semantic formulae are different from or consistent with adult counterparts and development patterns are rarely investigated and discussed. 
To fill the research gap, this paper contributes to the literature on L2 refusals by (1) showing the refusal styles of different age groups of teenage L2 learners regarding the patterns, order, and content of the refusals' semantic formulae in an oral production task from a cross-sectional perspective and (2) discussing the findings with reference to the refusal styles of these learners' adult counterparts and native Chinese (L1) speakers, as reported in the literature. The L2 refusals were produced by three groups of teenage Chinese English learners in Hong Kong whose first language is Cantonese. The students, aged 14-18, were studying in Forms 2, 4, and 6 in three secondary schools during the research period. They were asked to express refusals in six social situations in response to equalequal and to low-high requests. The findings not only indicate the development of their direct-then-indirect L2 refusals and L2 pragmatic competence, which resemble those related to L2 requesting and complaining reported in the literature, but they also lend some support to L1 pragmatic transfer, which favors indirectness while providing specific reasons when adult native Chinese speakers refuse requests.

\section{Literature review}

Over the past two decades, a number of studies have compared the order, frequency, and content of the semantic formulae of L1 refusals produced by native speakers of different languages and of L2 refusals made by nonnative language learners having varied proficiency levels (e.g., Allami and Naeimi 2011; Bella 2014) or different lengths of residence in the target community (e.g., Bella 2011; Félix-Brasdefer 2006; Sadeghi and Savojbolaghchilar 2011; Ren 2012). Empirical data were collected mainly through a DCT or role play task and were used to analyze the semantic formulae of refusals based on Beebe et al.'s refusal classification system (1990). Findings showed that cultural speech norms contribute to the different semantic formulae of refusals. Moreover, an L2 learner's length of residence in the target community and level of proficiency affect the acquisition of native speaker norms. There are also signs of L1 pragmatic transfer in L2 refusals, which point to the need for developing the pragmatic knowledge of the target culture and using a wider range of refusal strategies. As the present paper focuses on the communication style and pragmatic competence of teenage Chinese English learners, it is imperative to review L1 refusals produced by native Chinese speakers and L2 refusals produced by Chinese English learners. The following sections discuss these two types of refusals. 


\subsection{Refusals in Chinese expressed by adult native Mandarin Chinese speakers}

Refusals in Chinese can be expressed indirectly and directly. According to Chen et al. (1995: 121-122), there are at least four idioms showing the different ways to refuse, such as refusing an offer with gratitude or without hesitation. Various studies on Chinese refusals expressed by adult Mandarin Chinese in Mainland China and Taiwan tend to agree that there is a strong preference for indirect refusals, supporting the Chinese indirect communication approach and the norm of politeness (Gao and Ting-Toomey 1998), as reported in the literature.

In an early study on native Mandarin Chinese speakers' refusals conducted by Chen et al. (1995), the authors asked 100 adult male and female Chinese who had resided in the United States for at least 2 years to write down their refusals within the contexts of 16 situations (eight requests, four suggestions, two invitations, and two offers) in three varied social and power hierarchies (high-low, equal-equal, and low-equal) in a DCT. They classified refusals into two types: substantive and ritual. Substantive refusals demonstrate congruence between the speaker's intention and action, whereas ritual refusals are marked by incongruence between intention and action and are realized by some formulaic expressions, such as太麻煩 (tài má fan 'bother you too much'). According to Beebe et al.'s refusal classification system (1990), in substantive refusals, providing a reason was the respondents' first choice when rejecting requests for permission, favors, and actions, rejecting suggestions for purchasing daily necessities and changing a writing topic, and rejecting invitations to a dinner or party, regardless of the hearer's social status. This strategy was considered to be the most effective, especially for rejecting a senior's request, as it mitigated the damage of the hearer's face by explaining why it was not possible to comply with the initiating act. More importantly, it confirmed the concept of face in the context of Chinese politeness by giving face to both the hearer and the speaker. Secondly, regret was the most preferred strategy in all the equal-equal situations, particularly for requests and invitations indicating the need to give an explicit answer: 不用了 (bú yòng le)/不需要了 (bù xū yào le 'no need'). Direct refusals also took place at different levels of the social hierarchy and ranked second to giving a reason for refusals of invitations and offers. As argued by Chen et al. (1995), they were used by speakers with the aim of reducing the hearer's cost, which is an indication of politeness. Dissuading an interlocutor was frequently used to refuse offers, as the speaker signaled to the hearer his or her face-giving act. In addition, refusal strategies were combined, the most preferred sequence being giving a reason and an alternative, as the former 
could mitigate the negative force of the act, while the latter could provide the hearer with a second choice.

In another study, Liao and Bresnahan (1996) compared refusals made by Mandarin Chinese speakers at a Taiwan university and native American English speakers in six request scenarios consisting of varied social and power relationships. Some notable findings included the use of fewer speech tokens by the former group than by the latter. In rejecting the request of a speaker with a higher status (e.g., a teacher's request), the Mandarin Chinese group would include the address form of the interlocutor and offer more specific reasons and politeness markers of apology such as 對不起 (duì bu qũ), 抱兼 (bào qiàn), or 不好意思 (bù hăo yì si), phrases that are equivalent to sorry, my apology, or excuse me in English respectively. Native Chinese students would not give a lesson or apply any principle of statement when rejecting friends. If rejecting according to a principle, they would say 我不想 (wǒ bù xiăng 'I don't want') or 不 (bù 'don't'). They would not ask for any reasons, nor would they use many politeness markers of apology when rejecting family members with whom they had close relationships. Their fewer speech tokens and shorter refusals were described as being economical and realizing the "diǎn-dào-wéi-zhǐ (點到為止) point-to-is-end - marginally touch the point politeness principle” (Liao and Bresnahan 1996: 724), meaning that there is limited or minimal elaboration on the content or reason of refusals.

Research studies conducted in the 2000s have continued to support the initial findings. Wang (2001), who compared Chinese and English refusals by Chinese university students in the mainland and their native English-speaking counterparts, found that the former group's rejections were more indirect than those of the latter group with respect to nine requests for favor, permission, advice, and action in a DCT. Yang (2008), who analyzed refusals to offers, invitations, requests, and suggestions based on 160 video clips of five Chinese television series in China, also showed that Chinese tended to refuse while using excuses or explanations in their requests for favor, permission, information, or advice. To show modesty, Chinese would, initially, indirectly decline offers of gifts, favors, opportunities, and ritual invitations. Linguistic expressions such as 太麻煩 (tài má fan 'bother you too much') and 不用 (bú yòng 'no need') were used. However, direct refusals would be made to show real intention and, if necessary, subjection to the social status and power distance of the interlocutors. The indirect communication pattern is confirmed by Hong (2011) and Guo (2012). Hong (2011) compared refusals of one's teacher's invitation as expressed by a group of native Mandarin Chinese speakers in the mainland and by Americans studying Chinese at an American university. The results showed that the native Chinese speakers used explanations as head acts to refuse 
more indirectly than the Americans studying Chinese. The former also addressed the recipient with a title, expressed thanks, apologized, provided an alternative, and promised a future event more frequently than did the latter. Guo (2012), who examined refusals to two requests, two invitations, three offers, and one suggestion in the contexts of varied social and power relations between adult native Chinese and American students in a DCT, confirmed indirect rejections to requests by Chinese, especially to someone of higher status or to colleagues, but not rejections to invitations, offers, and suggestions to intimates.

\subsection{Refusals in English made by Chinese English learners}

Apart from studies on refusals expressed in Chinese, there are few empirical studies on L2 refusals produced by Chinese English learners. The refusal style of university Chinese English learners has been found to be similar to that of adult native Chinese speakers. Chang (2009) conducted an empirical study that compared refusals made by two groups of English-major college seniors, Englishmajor freshmen, and Chinese-major sophomores in a Taiwan university, and native American English speakers. The respondents were asked to express refusals in 12 situations featuring requests, invitations, offers, and suggestions in a discourse completion questionnaire, based on the work of Beebe et al. (1990). She found that the four groups adopted a similar range of semantic formulae but that the native American English speakers used direct strategies, adjuncts, and vague excuses more than the other three groups. The Chinese tended to adopt more indirect strategies in both L1 and L2, but there were no significant differences among the three groups of students in the use of adjuncts. The author attributed the indirect refusal style and lack of adjuncts to the Chinese culture and language and called for the teaching of new expressions to remedy the differences rather than a change in the communication pattern.

In another study, Chang (2011) collected data on refusals produced by 45 female native American English-speaking college students and 45 female Chinese English learners from a university in central Taiwan via an oral DCT consisting of five situations (two requests, two invitations, and one offer) adapted from a paper by Beebe et al. (1990). Chang's (2011) analysis also confirmed the fact that the native American English speakers used significantly more direct strategies than did the Chinese learners of English. However, the differences in the use of adjuncts and indirect strategies between the two groups were not statistically significant. Both groups provided reasons while expressing indirect rejections, but the reasons provided by the Chinese English learners were more specific than those of the native American English speakers, 
particularly in refusing a senior's request. Chang attributed the reasons for this group's offer of specific details to the concept of miànzi and to Chen et al.'s view (1995: 122) regarding the need to 留面子 (liu miànzi 'preserve face for the refusee') and to 留後路 (liú hòulù 'leave oneself a way out'). A follow-up metapragmatic judgment questionnaire was conducted whereby 50 native American English speakers and 50 Chinese English learners were invited to rate the appropriateness of three direct and indirect refusal responses (from 1 "least appropriate" to 5 "most appropriate") given by Chinese English learners selected from each of the five situations in the first phase of the study. Nevertheless, there were no significant differences between the two groups in their ratings, indicating that the perception data in the second phase of the study were not congruent with the production data in the first phase of the study. Incongruence, according to Chang (2011), might be due to the limitations of closed role play.

In essence, empirical studies on both L1 and L2 refusals made by native Mandarin-speaking Chinese adults and university Chinese English learners have shown that they would reject requests, suggestions, and even invitations indirectly while providing specific reasons. The latter do not have any adjuncts in their refusals. Indirectness in refusals can be attributable to the concept of face (面子 miànzi) in Chinese collectivistic culture (Hofstede 2001), which is "concerned more about what other others think of one's worth, especially in the context of one's in-group and out-group, than about oneself" (Gao and TingToomey 1998: 54). Thus, indirectness, in the Chinese culture, can maintain the refusee’s face: 留面子 (liu miànzi), protect interpersonal relationships (Bond 1991), preserve harmony (Chang 2009, Chang 2011; Lee-Wong 2000; Li 2007), and respect the inside relationships encoded in the social hierarchical order (Bond and Kwang-Kuo 1986; Gu 1990; Li 2007; Li and Li 1996), which regards "authority, male gender, and age seniority in the superordinate position in the hierarchy" (Pan 2000: 78). The concept of miànzi, or face, in Chinese culture is different from the concept of face introduced by Brown and Levinson (1987). The former treats face as an interdependent phenomenon which is a dominant value in Asian cultures, whereas the latter treats face as an independent phenomenon that is a dominant value in Western cultures (Pan 2000). Therefore, in Chinese collectivistic culture, an act is performed according to the social norm of respecting hierarchical order by considering multiple interrelational factors, namely the relationship with/social distance from the interlocutor, the social status of the interlocutor, and the situation. However, there are situations in which direct refusals are used due to the hearer's social status and to the speaker's concern about reducing the hearer's cost (Chen et al. 1995). In this light, refusals produced by Chinese speakers, be they expressed by native Chinese speakers or by Chinese 
English learners, may not always be as categorically indirect as they could be, subject to one's relationship with the interlocutor or situation.

Up until now, empirical studies on refusals have collected their data mainly from adult native Mandarin speakers and university Mandarin-speaking learners of English by means of a written DCT. However, the refusal styles used by other learner age groups and in other regions of China, which can provide additional insights into the refusal style and pragmatic competence of Chinese English learners versus their adult counterparts and native Chinese (L1) speakers, have not been adequately explored. As pointed out by Mills and Kádár (2011), stereotyped speech norms or tendencies may be associated with only a particular group within a culture. Examining a wide range of data, such as those relating to young and old Chinese learners or speakers from different regions of the same country or those gathered via another data-collection method, may enable us to see how the norms are applied within the culture and how the speech act is performed by different groups.

\section{The study}

\subsection{Aim and research questions}

The study aimed to investigate the refusal style of young Chinese learners of English whose first language is Cantonese in Hong Kong secondary schools, and to discuss their refusal style based on that of university Chinese learners of English and adult native Chinese (L1) speakers reported in the literature. Hong Kong, which used to be a British colony, was returned to China in 1997 and is now a special administrative region of the country. In Hong Kong, 89.5\% of the Chinese population speaks Cantonese, which is a Yue spoken dialect, ${ }^{1}$ as the usual language. Cantonese-speaking citizens write standard written Chinese in formal and official documents, although some newspapers adopt the written form of Cantonese. Many written Cantonese words are the same as Mandarin words, but they are pronounced in a different way (Snow 2004). The Cantonesespeaking learners came from three groups of teenagers aged between 14 and 18 studying in different forms and represent increasing language-learning experience. They were asked to produce some refusals in an oral production task, and the data were analyzed from a cross-sectional perspective.

1 According to 2011 Population Census information at http://www.census2011.gov.hk/en/maintable/A111.html, $89.5 \%$ of population speaks Cantonese as their usual language in Hong Kong. 
To achieve the aim, two research questions were asked.

1. In what ways are the different groups of teenage Cantonese learners of English similar to or different each other in the order, frequency, and content of their refusals' semantic formulae in varied social and power hierarchical situations?

2. To what extent are the refusals of teenage Cantonese English learners similar to or different from those of their adult counterparts and of native Chinese (L1) speakers mentioned in the literature?

\subsection{Participants}

A total of 156 secondary Cantonese learners of English aged around 14, 16, and 18 studying in F2, F4, and F6 in three secondary schools ${ }^{2}$ in Hong Kong participated in the study. Fifty-five came from F2, 52 from F4, and 49 from F6. They were chosen primarily based on age and language-learning experience reflected through their forms of study, though there might be variations in language proficiency between individuals and schools.

\subsection{Instrument: Oral production task}

An oral production task was chosen as it allows researchers to elicit a large quantity of more spontaneous spoken data at a designated period of time in an experimental or a cross-sectional research study. The task is similar to the closed role play and DCT, which requires learners to make refusals in one turn only. Although role play has been criticized as not authentic and the participants may not act in the same way as they do in real-life communication, the task can reflect their behavior and speech in a defined and controlled context, and differences between natural and experimental data were found to be not significant (Chang 2011). The study requested learners of English to produce refusals in six situations about requests that were developed based on a preliminary survey, ${ }^{3}$ all of which were presented in context with varied social and power hierarchies.

2 It is recognized that there are individual variations in English proficiency within the school and across schools in different regions in Hong Kong.

3 Since the participants were teenagers, the social situations adopted in the DCTs of other research studies might not be applicable to them. In light of this, a preliminary survey was conducted. 
Following the research method used by Rose (2000) and the procedures described in his paper that investigated the development of young Cantonese English learners' requests, the researcher asked some secondary students to write down some refusal contexts and then developed characters for the oral production task. The most frequent refusals happened in the equal-equal and low-high hierarchies, including refusing requests from friends, classmates, parents, and relatives to play or work together, lend money, go out, and talk about study respectively. With reference to the two hierarchies, six similar situations were devised (Table 1) so that the participants would not have too much difficulty in responding. To facilitate elicitation, the researcher developed a main character and some peers and family members. The main character was called Bobby. The requests were brought up by his or her classmates, parents, or relatives. Then, the researcher invited a visual arts undergraduate to draw the social situations for the oral production task.

Table 1: Six contexts for requests and social/power hierarchies.

\begin{tabular}{|c|c|c|c|}
\hline Situation & Location & Type & Description \\
\hline 1 & school & equal-equal & $\begin{array}{l}\text { A classmate asked if Bobby could lend him some money. } \\
\text { Bobby tells the classmate that he can't lend the money. }\end{array}$ \\
\hline 2 & school & equal-equal & $\begin{array}{l}\text { A classmate asked Bobby to teach him how to do } \\
\text { homework. Bobby doesn't want to teach him. }\end{array}$ \\
\hline 3 & home & low-high & $\begin{array}{l}\text { Mum asked Bobby to do some housework. Bobby doesn't } \\
\text { want to do the assigned housework. }\end{array}$ \\
\hline 4 & home & low-high & $\begin{array}{l}\text { Uncle asked if Bobby wanted to watch a movie with him. } \\
\text { Bobby doesn't want to watch the movie with his uncle. }\end{array}$ \\
\hline 5 & home & low-high & $\begin{array}{l}\text { Mum asked Bobby about his study and academic } \\
\text { performance. Bobby doesn't want to tell mum his study } \\
\text { problem. }\end{array}$ \\
\hline 6 & school & low-high & $\begin{array}{l}\text { A senior girl asked if she could team up with Bobby in an } \\
\text { activity. Bobby doesn't want to team up with her. }\end{array}$ \\
\hline
\end{tabular}

\subsection{Procedures and data analysis}

On the day of the research, the participants came to see the researcher and a research assistant in groups in a room assigned by the school authority according to the planned schedule. Before asking the participants to perform the speech act, the researcher briefed them about the aim of the study and recording and rehearsed the oral task once. The researcher showed a picture and asked, "If you were Bobby, what would you say?” The rehearsal allowed the subjects to 
practice one to two times so as to familiarize them with the procedure and have them get used to speaking in front of a small audio recorder. Their oral discourse was recorded and transcribed verbatim. Incomplete or incomprehensible discourse was removed from the database. Then the transcribed discourse was categorized, and only the instances agreed by both the researcher and the research assistant were tallied and analyzed. The difference in strategy use among the three groups was analyzed statistically using the Pearson chi-square test. Their recordings were discarded after the research. As the initiating acts of the six situations were requests, the participants' L2 refusals would be discussed with particular reference to how refusals to requests were made by adult native Chinese speakers and university Chinese English learners, in terms of their similarities or differences in communication style and preferred refusal strategies reported in Sections 2.1 and 2.2.

\subsection{A prepared list of categories}

The act of refusal can be expressed in myriad ways according to varied social and power relationships, resulting in a host of direct and indirect categories. Beebe et al.'s (1990) categories have been widely used by researchers since the 1990s for both oral- and written-discourse analysis. A similar list of categories was adopted for the study. However, face-to-face-specific categories, such as lack of enthusiasm, doing nothing, and physical departure were not included. Table 2 is a summary of the prepared list of categories, illustrated with examples extracted from either the participants' discourse in the study or Beebe et al.'s (1990) paper.

\section{Findings}

\subsection{Order and frequency of refusal strategies}

A total of 896 utterances were collected from the six contexts. Coding was first performed by a research assistant and counterchecked by the researcher. Only 860 utterances were analyzed, as incomplete or incomprehensible utterances and those disputed by the research assistant and the researcher were removed from the database. It was found that the three groups of secondary Cantonese learners of English used single strategies most (416 instances), followed by the combination of two single strategies (343 instances) and the combination of three single strategies (101 instances). The difference in the use of a single strategy or two-strategy combination among the three groups was significant 
Table 2: Coding categories of refusal.

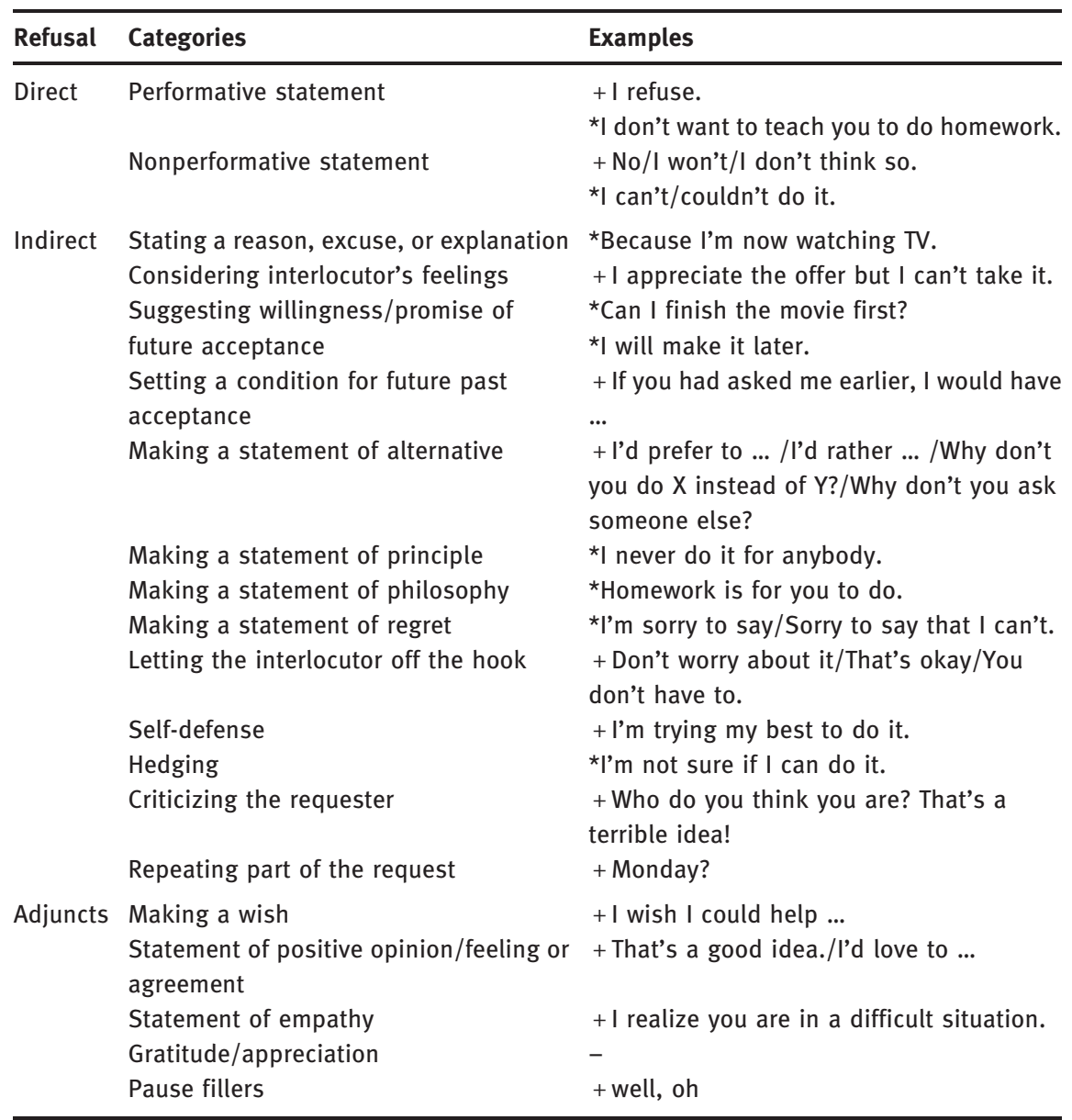

Note: Examples with an asterisk $\left(^{\star}\right)$ are taken from the participants' oral discourse while examples with a plus sign (+) are extracted from Beebe et al.'s paper (1990: 72-73).

statistically $(p<0.05)$ according to the Pearson chi-square test whereas the difference in the use of three-strategy combinations was not (Table 3).

\section{Pattern 1: Using one refusal strategy}

Twelve single strategies were identified (Table 4) from the six situations. Two of them were direct strategies, and 10 were indirect strategies. All three groups of 
Table 3: Frequency rate, percentage, and statistical difference for each type of strategy by students' level of study.

\begin{tabular}{lrrrrl}
\hline Strategies & F2 & F4 & F6 & Total & Pearson chi-square test result \\
\hline One & 151 & 135 & 130 & 416 & $p=0.001$, significant difference \\
Two & 121 & 115 & 107 & 343 & $p=0.020$, significant difference \\
Three or more & 42 & 34 & 25 & 101 & $p=0.804$, no significant difference \\
& 314 & 284 & 262 & 860 & \\
\hline
\end{tabular}

Note: $p<0.05$ is significant.

Table 4: Frequency rates and percentages of the L2 single refusal strategies by students' level of study.

\begin{tabular}{lrrrr}
\hline Single strategy & F2 & F4 & F6 & Total \\
\hline $\begin{array}{l}\text { Making a direct performative statement } \\
\text { Making a direct nonperformative }\end{array}$ & $\frac{50(33.1 \%)}{7(4.6 \%)}$ & $\frac{28(20.7 \%)}{5(3.7 \%)}$ & $\frac{17(13.1 \%)}{4(3.1 \%)}$ & $\frac{95(22.8 \%)}{16(3.8 \%)}$ \\
$\quad$ statement & & & & \\
Stating a reason/excuse/explanation & $\frac{58(38.4 \%)}{6(4.0 \%)}$ & $\frac{59(43.7 \%)}{8(5.9 \%)}$ & $\frac{59(45.4 \%)}{6(4.6 \%)}$ & $\frac{176(42.3 \%)}{20(4.8 \%)}$ \\
Making a promise of future acceptance & $0(0.0 \%)$ & $0(0.0 \%)$ & $1(0.8 \%)$ & $1(0.2 \%)$ \\
Setting a condition for future & $1(0.7 \%)$ & $10(7.4 \%)$ & $9(6.9 \%)$ & $20(4.8 \%)$ \\
$\quad$ acceptance & $0(0.0 \%)$ & $0(0.0 \%)$ & $1(0.8 \%)$ & $1(0.2 \%)$ \\
Making a statement of alternative & $10(6.6 \%)$ & $9(6.7 \%)$ & $7(5.4 \%)$ & $26(6.3 \%)$ \\
Making a statement of philosophy & $15(9.9 \%)$ & $14(10.4 \%)$ & $22(16.9 \%)$ & $51(12.3 \%)$ \\
Making a statement of regret & $4(2.6 \%)$ & $0(0.0 \%)$ & $2(1.5 \%)$ & $6(1.4 \%)$ \\
Letting the interlocutor off the hook & $0(0.0 \%)$ & $0(0.0 \%)$ & $2(1.5 \%)$ & $2(0.5 \%)$ \\
Defending oneself & $0(0.0 \%)$ & $2(1.5 \%)$ & $0(0.0 \%)$ & $2(0.5 \%)$ \\
Criticizing the request/requester & $151(100 \%)$ & $135(100 \%)$ & $130(100 \%)$ & $416(100 \%)$ \\
Expressing a wish & & & & \\
Total & & &
\end{tabular}

Note: The three most frequently used single strategies are underlined.

L2 learners consistently refused indirectly first by giving a reason, followed by the direct performative statement. The three most outstanding strategies were stating a reason, excuse, or explanation (176 instances, 42.3\%), making a direct performative statement (95 instances, $22.8 \%$ ), and letting the interlocutor off the hook (51 instances, $12.3 \%$ ). Of the three single refusal strategies, the frequency of the direct performative strategy decreased gradually from F2 to F6, but that of the two indirect ones remained steady. Other identified single strategies included making a promise of future acceptance, setting a condition for future acceptance, stating an alternative, a regret, or one's philosophy, criticizing the request/requester, 
Table 5: Pearson chi-square test results.

\begin{tabular}{lrrr}
\hline Strategy type & Value & df & Asymp. Sig. (2-sided) \\
\hline Single strategy & $43.131($ a) & 22 & 0.005 \\
Two-strategy combination & $61.720($ a) & 46 & 0.061 \\
Three-strategy combination & $23.260($ a) & 30 & 0.804 \\
\hline
\end{tabular}

Note: $p<0.05$ is significant.

defending oneself, and making a wish. The frequency rates of these single strategies are comparatively lower than the three top strategies. According to the Pearson chi-square test, the difference in the use of the 12 single strategies across the three groups was found to be significant, $p<0.05$ (Table 5).

\section{Pattern 2: Combining two refusal strategies}

In addition to the use of single refusal strategies, the three groups of learners combined two single strategies in their refusals. Twenty-four two-strategy combinations were identified. The most frequent pattern was to combine a reason, excuse, or explanation with a statement of regret (I'm sorry) (141 instances, 41.1\%). The next pattern was to combine a direct performative statement with an indirect strategy such as a statement of regret (39 instances, $11.4 \%$ ) or a reason (30 instances, $8.7 \%$ ) (Table 6). ${ }^{4}$ The difference in the use of the 24 combinations among the three groups of students was not significant statistically, $p=.061$ (Table 5). The top three strategies were as follows:

Table 6: Frequency rates and percentages of the top three two-strategy combinations by students' level of study.

\begin{tabular}{lrrrr}
\hline Two-strategy combination & F2 & F4 & F6 & Total \\
\hline [Reason] + [statement of regret] & $38(31.4 \%)$ & $50(43.5 \%)$ & $53(49.5 \%)$ & $141(41.1 \%)$ \\
$\begin{array}{l}\text { [Direct performative] + [statement } \\
\quad \text { of regret] }\end{array}$ & $16(13.2 \%)$ & $13(11.3 \%)$ & $10(9.3 \%)$ & $39(11.4 \%)$ \\
[Direct performative] + [reason] & $17(14 \%)$ & $11(9.6 \%)$ & $2(1.9 \%)$ & $30(8.7 \%)$ \\
\hline
\end{tabular}

4 As the other combinations occurred only once or twice, they are not presented in this paper. 
1. [Stating a reason] + [making a statement of regret]

2. [Making a direct performative statement] + [making a statement of regret]

3. [Making a direct performative statement] + [stating a reason]

\section{Pattern 3: Combining three refusal strategies}

Sixteen three-strategy combinations were found. However, the number of instances of each combination was low, and the difference in the use of the 16 combinations among the three groups of students was not statistically significant, $p<0.804$ (Table 5). The majority of the students tended to combine a direct refusal strategy with two indirect ones. The top three strategies were as follows (Table 7):

Table 7: Frequency rates and percentages of the top three-strategy combinations by students' level of study.

\begin{tabular}{lrrrr}
\hline Three-strategy combination & F2 & F4 & F6 & Total \\
\hline $\begin{array}{c}\text { [Nonperformative] + [reason] } \\
+ \text { [statement of regret] }\end{array}$ & $12(28.6 \%)$ & $15(44.1 \%)$ & $6(24 \%)$ & $33(32.7 \%)$ \\
$\begin{array}{c}\text { [Reason] + [alternative] + [statement } \\
\text { of regret] }\end{array}$ & $10(23.8 \%)$ & $4(11.8 \%)$ & $6(24 \%)$ & $20(19.8 \%)$ \\
$\begin{array}{c}\text { [Performative] + [reason] + [statement } \\
\text { of regret] }\end{array}$ & $8(19.0 \%)$ & $5(14.7 \%)$ & $5(20.0 \%)$ & $18(17.8 \%)$ \\
\hline
\end{tabular}

1. [Making a nonperformative statement $]+[$ stating a reason $]+[$ making a statement of regret]

2. [Stating a reason] + [making a statement of alternative $]+[$ making a statement of regret]

3. [Making a direct performative statement $]+[$ stating a reason $]+[$ making a statement of regret]

\subsection{Order and frequency of refusal strategies by situation}

It was found that the three groups of learners adopted very similar refusal strategies in the six situations. The strategy of stating a reason was found in all three patterns. The majority of the learners stated a reason for situations 1 to 4, except in situations 5 and 6, when they adopted a single strategy (Table 8). When they extended their refusals' length, they would state a reason and give a 
Table 8: Frequency rate of the most popular single strategy (Pattern 1) by situation.

\begin{tabular}{llrrrr}
\hline Situation & Strategy & F2 & F4 & F6 & Total \\
\hline $1(\mathrm{E}-\mathrm{E})$ & Stating a reason & $13(54.2 \%)$ & $13(68.4 \%)$ & $11(64.7 \%)$ & $37(61.7 \%)$ \\
$2(\mathrm{E}-\mathrm{E})$ & Stating a reason & $9(56.3 \%)$ & $5(41.7 \%)$ & $3(33.3 \%)$ & $17(45.9 \%)$ \\
$3(\mathrm{~L}-\mathrm{H})$ & Stating a reason & $14(51.9 \%)$ & $13(61.9 \%)$ & $22(81.5 \%)$ & $49(65.3 \%)$ \\
$4(\mathrm{~L}-\mathrm{H})$ & Stating a reason & $18(81.8 \%)$ & $14(63.6 \%)$ & $9(56.3 \%)$ & $41(68.3 \%)$ \\
$5(\mathrm{~L}-\mathrm{H})$ & Letting the interlocutor off & $14(43.8 \%)$ & $14(37.8 \%)$ & $22(57.9 \%)$ & $50(46.7 \%)$ \\
& the hook & $26(86.7 \%)$ & $10(41.7 \%)$ & $6(26.1 \%)$ & $42(54.5 \%)$ \\
$6(\mathrm{~L}-\mathrm{H})$ & Direct performative & & & & \\
\hline
\end{tabular}

Table 9: Frequency rate of the most popular two-strategy combinations (Pattern 2) by situation.

\begin{tabular}{|c|c|c|c|c|c|}
\hline Situation & Strategy & F2 & F4 & F6 & Total \\
\hline $1(E-E)$ & $\begin{array}{l}\text { [Reason] }+ \text { [statement } \\
\text { of regret] }\end{array}$ & 12 (50\%) & $12(54.6 \%)$ & 14 (66.7\%) & 38 (56.7\%) \\
\hline $2(E-E)$ & $\begin{array}{l}\text { [Reason] }+ \text { [statement } \\
\text { of regret] }\end{array}$ & 7 (33.3\%) & $11(50 \%)$ & $12(50 \%)$ & 30 (44.8\%) \\
\hline $3(\mathrm{~L}-\mathrm{H})$ & $\begin{array}{l}\text { [Reason] }+ \text { [statement } \\
\text { of regret }]\end{array}$ & 7 (38.9\%) & 7 (33.3\%) & 7 (43.8\%) & $21(38.2 \%)$ \\
\hline $4(\mathrm{~L}-\mathrm{H})$ & $\begin{array}{l}\text { [Reason] }+ \text { [statement } \\
\text { of regret }]\end{array}$ & $6(23.1 \%)$ & $8(44.4 \%)$ & $12(50 \%)$ & $26(38.2 \%)$ \\
\hline $5(\mathrm{~L}-\mathrm{H})$ & $\begin{array}{l}\text { [Direct performative] }+ \\
\text { [statement of regret] }\end{array}$ & 2 (16.7 \%) & $3(37.5 \%)$ & 2 (33.3\%) & 7 (26.9\%) \\
\hline $6(\mathrm{H}-\mathrm{L})$ & $\begin{array}{l}\text { [Reason] }+ \text { [statement } \\
\text { of regret }]\end{array}$ & $5(25 \%)$ & $12(50 \%)$ & 7 (43.8\%) & $24(40 \%)$ \\
\hline
\end{tabular}

statement of regret for situations 1 to 4 and 6 when they combined two strategies (Table 9), and they would add a nonperformative statement to these situations when they combined three strategies (Table 10). The only variations happened in situation 5, which was a refusal to a request from a parent regarding study, and in situation 6, where a refusal was made to an offer from a senior-form student. According to the Pearson chi-square test results, there was no significant difference in frequency rates of the three patterns among the three groups by situation, $p<0.05$ (Tables 11-13), except situation 6 in pattern $1(p=.001)$ (Table 11).

\subsection{Content of refusals}

The students provided specific reasons or excuses for different situations, including personal and internal physical problem, emotion, and preference. The first 
Table 10: Frequency rate of the most popular three-strategy combinations (Pattern 3) by situation.

\begin{tabular}{|c|c|c|c|c|c|}
\hline Situation & Strategy & F2 & F4 & F6 & Total \\
\hline $1(E-E)$ & $\begin{array}{l}\text { [Nonperformative] }+ \text { [reason }]+ \\
\text { [statement of regret] }\end{array}$ & $3(75 \%)$ & $5(83.3 \%)$ & $2(66.7 \%)$ & $10(76.9 \%)$ \\
\hline $2(E-E)$ & $\begin{array}{l}\text { [Nonperformative] }+[\text { reason }]+ \\
\text { [statement of regret }]\end{array}$ & $2(16.7 \%)$ & $6(42.9 \%)$ & $2(28.6 \%)$ & $11(28.2 \%)$ \\
\hline $3(\mathrm{~L}-\mathrm{H})$ & $\begin{array}{l}\text { [Nonperformative] }+[\text { reason }]+ \\
\text { [statement of regret] }\end{array}$ & $3(33.3 \%)$ & $3(60 \%)$ & $1(25 \%)$ & $7(38.9 \%)$ \\
\hline $4(\mathrm{~L}-\mathrm{H})$ & $\begin{array}{l}\text { [Reason] }+ \text { [alternative }]+ \\
{[\text { statement of regret }]}\end{array}$ & $3(50 \%)$ & $2(22.2 \%)$ & $5(71.4 \%)$ & $19(45.5 \%)$ \\
\hline $5(\mathrm{~L}-\mathrm{H})$ & - & - & - & - & - \\
\hline $6(\mathrm{~L}-\mathrm{H})$ & $\begin{array}{l}\text { [Performative] }+ \text { [reason] }+ \\
\text { [statement of regret] }\end{array}$ & $2(50 \%)$ & - & $2(50 \%)$ & $4(50 \%)$ \\
\hline
\end{tabular}

Table 11: Pearson chi-square test results for a single strategy (Pattern 1).

\begin{tabular}{lrrr}
\hline Situation & Value & df & Asymp. Sig. (2-sided) \\
\hline $1(\mathrm{E}-\mathrm{E})$ & $5.334(\mathrm{a})$ & 10 & 0.868 \\
$2(\mathrm{E}-\mathrm{E})$ & $18.093(\mathrm{a})$ & 16 & 0.319 \\
$3(\mathrm{~L}-\mathrm{H})$ & $7.828(\mathrm{a})$ & 6 & 0.251 \\
$4(\mathrm{~L}-\mathrm{H})$ & $9.541(\mathrm{a})$ & 6 & 0.145 \\
$5(\mathrm{~L}-\mathrm{H})$ & $22.716(\mathrm{a})$ & 18 & 0.202 \\
$6(\mathrm{~L}-\mathrm{H})$ & $26.764(\mathrm{a})$ & 8 & 0.001 \\
\hline
\end{tabular}

Note: $p<0.05$ is significant.

Table 12: Pearson chi-square test results for two-strategy combinations (Pattern 2).

\begin{tabular}{lrrr}
\hline Situation & Value & Df & Asymp. Sig. (2-sided) \\
\hline $1(\mathrm{E}-\mathrm{E})$ & $3.020(\mathrm{a})$ & 4 & 0.554 \\
$2(\mathrm{E}-\mathrm{E})$ & $36.763(\mathrm{a})$ & 18 & 0.006 \\
$3(\mathrm{~L}-\mathrm{H})$ & $15.268(\mathrm{a})$ & 18 & 0.644 \\
$4(\mathrm{~L}-\mathrm{H})$ & $20.667(\mathrm{a})$ & 14 & 0.110 \\
$5(\mathrm{~L}-\mathrm{H})$ & $24.685(\mathrm{a})$ & 28 & 0.645 \\
$6(\mathrm{~L}-\mathrm{H})$ & $19.254(\mathrm{a})$ & 18 & 0.376 \\
\hline
\end{tabular}

Note: $p<0.05$ is significant.

person pronoun I prevailed. Personal financial inadequacy was specifically mentioned for situation 1. Emotion, unavailability, and physical fatigue were quoted for situations 2, 3, and 4. Personal/teacher's responsibility and unavailability were referred to for situation 5 , and personal preference, gender problem, and 
Table 13: Pearson chi-square test results for three-strategy combinations (Pattern 3).

\begin{tabular}{lrrr}
\hline Situation & Value & df & Asymp. Sig. (2-sided) \\
\hline $1(\mathrm{E}-\mathrm{E})$ & $3.033(\mathrm{a})$ & 4 & 0.552 \\
$2(\mathrm{E}-\mathrm{E})$ & $25.419(\mathrm{a})$ & 22 & 0.277 \\
$3(\mathrm{~L}-\mathrm{H})$ & $6.110(\mathrm{a})$ & 8 & 0.635 \\
$4(\mathrm{~L}-\mathrm{H})$ & $9.653(\mathrm{a})$ & 10 & 0.471 \\
$5(\mathrm{~L}-\mathrm{H})$ & - & - & - \\
$6(\mathrm{~L}-\mathrm{H})$ & $1.333(\mathrm{a})$ & 2 & 0.513 \\
\hline
\end{tabular}

Note: $p<0.05$ is significant.

unavailability for situation 6. Among the nine most frequently mentioned reasons, only teacher's responsibility and gender problem were external issues. The following summarizes the specific reasons or excuses for each situation.

Situation 1: I have no money/do not have enough money.

I am poor.

I forgot to bring my wallet.

Situation 2: I am not happy/not in a good mood/in a bad mood.

I don't know how to do.

I don't have time to help you.

I am not available or free.

I do not feel well/I feel tired.

I have something to do.

Situation 3: I am busy/tired/depressed.

I have something important to do/a lot of homework to do.

I don't have time.

Situation 4: The film is boring/difficult to understand

I don't like/am not interested in this film.

I am not free today.

I am going to sleep.

... because I hate violence.

Situation 5: I am not feeling well/want to go to bed.

I lost my report card.

My teacher hasn't given me the report card.

I had many things I don't know or understand.

Situation 6: I am sick.

I don't like you because you are a girl. 
My friend wants me to team up with him/I am already in another group/have a team/a partner.

I like to play with boys/don't want to team up with girls.

I'm too young and not suitable for you.

Girls and boys should not get into one group. It may cause some trouble.

\subsection{Pramalinguistic devices}

The three groups of students always used the phrase of I don't want to for the direct performative statement. The frequency rate of this phrase decreased from 92 instances (F2 students) to 58 (F4 students) to 40 (F6 students) (Table 14). On the other hand, the phrase I can't was commonly used for the direct nonperformative statement. When the students stated a reason or explanation, the subordinate clause of 'because $+\mathrm{NP}+\mathrm{V}+$ complement' appeared in conjunction the direct (non)performative statement or a statement of regret before refusing occasionally. For instance,

- I don't want to teach you homework because I'm not in a good mood. (RE2, F2)

- Sorry, I don't want to team up with you. (RE6, F2)

- I'm so sorry. I cannot lend the money. (RE1, F4)

- I can't team up with you. (RE6, F4)

Table 14: Frequency rates of corresponding linguistic devices by students' level of study.

\begin{tabular}{lrrr}
\hline Strategies and corresponding linguistic devices & F2 & F4 & F6 \\
\hline Direct performative: I don't want to & 92 & 58 & 40 \\
Direct nonperformative: I cannot / I can't ... & 30 & 32 & 27 \\
Suggesting an alternative: Can I ...? & 10 & 14 & 7 \\
Suggesting an alternative: Can you ...? & 9 & 10 & 8 \\
Suggesting an alternative: Could you ...? & 0 & 0 & 2 \\
Suggesting an alternative: Shall we ...? & 0 & 1 & 0 \\
Making a statement of regret: Sorry/l'm sorry (initial position) & 121 & 123 & 105 \\
Making a statement of regret: Sorry/l'm sorry (final position) & 5 & 4 & 7 \\
\hline
\end{tabular}

A lot of students expressed regret by using I'm (so) sorry or sorry either at the initial or final position of a direct refusal. The regret also served as a politeness device to soften the force of rejection in the context. When they provided an alternative, they would use an imperative statement or a suggestive tone in the requestive form of Can/Could I/you? Some students often added oh or occasionally well to mitigate the act. For instance, 
- I am sorry I can't help you. Go and ask other classmates, maybe they can help you. (RE1, F2)

- I can't lend you any money. I'm sorry. (RE1, F4)

- So can you ask other people for help? (RE2, F6)

- I don't like this film. Shall we watch another film? (RE4, F4)

- Oh, I don't have any money. (RE1, F2)

- Well, mum, I don't want to talk about this. (RE5, F6)

\section{Discussion}

The findings provide useful evidence to answer the two research questions and shed some light on the communication style of teenage Cantonese learners of English, the trajectory of L2 refusal development, L1 pragmatic transfer, and pragmatic competence.

\subsection{Refusal styles of teenage Cantonese English learners with respect to $L 2$ requests: Signs of $L 1$ indirect communication styles and the trajectory of L2 refusal development}

The findings show that three groups of teenage Cantonese English learners in Hong Kong frequently refuse requests indirectly in the two social and power English hierarchies, representing a total of approximately $73 \%$ of all identified single strategies (Table 4), regardless of age or situation. An indirect refusal often begins by using the strategy of giving a reason as the head act. This strategy is found to be the most frequently used in patterns 1,2 , and 3 - single strategy and two- and three-strategy combinations (Tables 5-7) - by the three groups and in four out of six situations (Tables 8-10). The teenage learners further express indirectness by combining two and even three strategies. The most preferred combination is the provision of a reason together with a statement of regret (Table 6), and the direct strategy of making a nonperformative statement serves as the head act, followed by the two most preferred indirect strategies (Table 7). The reasons or explanations provided by the three groups of learners are specific and usually related to personal responsibility, preference, or a problem, followed by some external factors, such as teacher responsibility or gender issues (see Section 4.3).

Similar to what is reported on L1 and L2 refusals made by adult native Chinese speakers and university Chinese English learners in mainland China and Taiwan 
(Chang 2009 and Chang 2011; Guo 2012; Li 2007; Liao and Bresnahan 1996; Wang 2001; Yang 2008), teenage L2 learners in Hong Kong frequently use the indirect strategy of giving a specific reason and combining it with a statement of regret. Other researchers attribute the indirect refusal style to the inherent social hierarchy in Chinese culture (Bond and Kwang-Kuo 1986). Specifying a reason or providing an explanation is a glossed-over realization of the concept of miànzi and politeness by giving face to both the hearer and to the speaker, reciprocally. A statement of regret, though serving as a signal that there will be no further negotiation, is argued by Chen et al. (1995: 146) to be a speaker's polite expression of "noncompliance without damaging H's miànzi." Moreover, the teenage learners' L2 strategies occur in combination with other strategies. The combination of giving a reason and a statement of regret is consistent with what was reported in Liao and Bresnahan's study (1996). As similar L1 features are also seen from the teenage learners' L2 refusal communication style, it seems to indicate that pragmatic transfer takes place not only in adulthood but also in the teens.

Nevertheless, one noticeable difference between the refusal strategies of teenage Cantonese English learners and those of adult Chinese English learners and L1 Chinese speakers is the inclination to reject requests directly, especially in situation 6 (see Table 1), where refusal is expressed to a senior schoolmate. Although direct refusals can be made subject to situations and to the interlocutor's social status in Chinese culture (Chen et al. 1995), the 14-year-old group tends to adopt more direct refusals than the other two groups, as the direct performative statement is still one of the top three single strategies in pattern 1 (Table 4). The expression of no or I don't want serves the function of 一口拒絕 (yīkǒu huìjué), which is also used by native Chinese speakers in L1 refusals (Liao and Bresnahan 1996). The frequent use of I don't want for the direct performative, particularly by the 14-year-old group (Table 14), seems to focus more on an individual's desire than on interpersonal harmony, the latter of which is highly valued in Chinese culture and social hierarchy (Bond and Kwang-Kuo 1986; Chang 2009, Chang 2011; Hong 2011). Personal feelings or preferences seem to be more important among teenage learners than preserving face (留面子) for peers and relatives or leaving a way out (留後路) for oneself (Chen et al. 1995), which is an area of concern for many adult Chinese speakers. It is worth noting that the frequency rates of direct performative statements and the corresponding expression of $I$ don't want to gradually decline as age and language exposure increase (Tables 4 and 14). Directness is later replaced by the combination of both direct and indirect refusal styles (Tables 6 and 7). They begin to combine two or more single direct and indirect strategies in their responses, as shown in patterns 2 and 3.

Although the present study was conducted on a small scale, and its data were collected via a closed oral production task in the equal-equal and low- 
high social contexts, the progression from a single strategy to combined strategies and the direct-then-indirect shift have shed some light on the trajectory from directness to indirectness of L2 refusal development in teenage Cantonese English learners. The trajectory of L2 refusal development is consistent with that of L2 requesting (Rose 2000, Rose 2009) and L2 complaining (Lee 2012), as demonstrated by young Cantonese English learners in the literature.

\subsection{Sociopragmatic and pragmalinguistic competence of teenage Cantonese English learners in refusing requests}

The three groups of learners demonstrate their sociopragmatic competence in the ways they manage the speech act in situations, especially in situations 5 and 6 . Although the learners' sociopragmatic competence seems to be limited, as shown from their use of the same single refusal strategy - stating a reason in four out of six equal-equal and low-high social situations (Table 8) - and the combination reason and regret statements in five out of six situations (Tables 9 and 10), they indeed act appropriately according to the request nature and relationship with interlocutors. An examination of the relationship between the interlocutors and the refuser (i.e., Bobby) reveals that they have an inside relationship (Scollon and Scollon 1991) and that the hierarchical relationship determines what refusal and face strategies should be used. A reason or explanation is usually given for situations 1 through 4, because the interlocutors are in-group members, and the reason helps to maintain good in-group relationships and to show respect, especially to parents and relatives, when their requests for favors or actions are denied. Variability is relatively low. However, the different request nature in situation 5 and the outside relationship with the interlocutor in situation 6 affect the stereotyped pattern. The strategy of "letting the interlocutor off the hook" is the learner's highly preferred single strategy for situation 5 (Table 8), whereas the direct performative strategy is the most popular one (Table 8) for situation 6 . A closer examination of the two situations shows that the nature of the request in situation 5 is about academic performance, and the interlocutor in situation 6 is a senior girl at school who is neither Bobby's classmate nor his friend. Facing a request about academic performance, which is a major concern of Chinese parents (Ho 1986), the teenage learners are sensitive to the given situation and react to it by asking their parents not to worry. Telling a mother that one can manage study and not to worry about one's academic achievement can dissuade her from asking further questions. It also indicates an attempt to avoid giving an answer by showing her respect, as required in Chinese social hierarchy (Bond and Kwang-Kuo 1986; Chang 2009, Chang 2011; Hong 2011). 
In addition, refusing a senior girl with whom one has only an occasional and temporary relationship can be different from refusing someone with whom one has an inside relationship, with reference to Chinese insider and outsider relationships (Bond and Kwang-Kuo 1986; Li and Li 1996). Limited miànzi will be given, as it will not pose a serious threat to harmony or to connection. Therefore, direct expressions of no or I don't want to team up with you are made to the girl. The learners' thoughts shape the content of the acts, and their choices reflect flexibility, demonstrating both their sociopragmatic competence in handling different equal-equal and low-high requests and the essence of Chinese culture in L2.

Although the learners are able to choose appropriate strategies in the face of different request natures and relations with the refusee, they make little variation in refusal strategies and demonstrate limited corresponding paralinguistic resources. Nearly all of them express the performative and nonperformative statements and regrets with the phrases I don't want, I cannot/can't, and sorry/ I'm sorry and use the strategy of stating a reason among the three groups and across the six situations. Those phrases are equivalent to 我不想 (wǒ bù xiăng 'I don't want') and 對不起 (duì bu q̌ 'sorry') in Mandarin Chinese, as used by native Chinese speakers (Liao and Bresnahan 1996). Despite other indirect strategies, such as suggesting the use of an alternative, the suggested alternative is presented mainly in the requestive form of Can you/I. The only adjunct to refusal is the word oh. The lack of adjunct is found to be a feature prevalent not only in native Chinese speakers' and university Chinese English learners' refusals (Chang 2009) but also in those expressed by teenagers. The limited linguistic devices and corresponding strategies merit attention. There is no mention of any other feeling: gratitude, appreciation, or positive opinion, before or after the refusal (Table 4). As a direct (non)performative statement is accompanied by an indirect strategy, such as offering a reason or a statement of regret to soften the effect, the refusal might sound unthoughtful when there is an absence of appreciation for the offer or invitation. The data, though limited and elicited only from an oral production task in the equal-equal and low-high social contexts, have provided a glimpse into teenage learners' refusal style and their interlanguage pragmatic competence.

\section{Conclusion}

In conclusion, the cross-sectional study has provided some evidence on teenage Cantonese English learners' refusal style and the differences and similarities with that of learners' adult counterparts and Chinese speakers. It has revealed the L2 refusals' semantic formulae and the contents used by the three age 
groups of teenage Cantonese English learners in two social situations. The teenage learners embrace indirect refusal communication style, which is consistent with the indirect communication style in Chinese culture. Signs of L1 pragmatic transfer are seen from their L2 refusals. They also demonstrate sociopragmatic competence and the essence of Chinese culture of face in different request natures and relationships with interlocutors by adopting varied indirect and direct L2 refusal strategies. However, the variety of refusal strategies is still limited, and the linguistic devices merit attention. More importantly, the directthen-indirect shift in L2 refusal development is consistent with that in L2 request, complaint, and pragmatic comprehension development in young Cantonese English learners in empirical studies. More data, particularly reallife longitudinal data from various social contexts, should be collected to confirm the findings of the cross-sectional study, L1 pragmatic transfer, and the trajectory of interlanguage pragmatic development.

Funding: The study is part of the outcome of a General Research Fund project (No. 242507) funded by the Hong Kong Research Grants Council. I am very grateful to the students and teachers who participated in and provided assistance in the study.

\section{References}

Achiba, Machiko. 2003. Learning to request in a second language: A study of child interlanguage pragmatics. Clevedon, UK \& Buffalo, NY: Multilingual Matters.

Allami, Hamid \& Amin Naeimi. 2011. A cross-linguistic study of refusals: An analysis of pragmatic competence development in Iranian EFL learners. Journal of Pragmatics 43. 385-406.

Bardovi-Harlig, Kathleen \& Beverly S. Hartford. 1993. Learning the rules of academic talk: A longitudinal study of pragmatic development. Studies in Second Language Acquisition 15. 279-304.

Beebe, Leslie M., Tomoko Takahashi \& Robin Uliss-Weltz. 1990. Pragmatic transfer in ESL refusals. In Robin C. Scarcella, Elaine S. Andersen \& Stephen Krashen (eds.), Developing communicative competence in a second language, 55-73. Boston: Heinle and Heinle.

Bella, Spyridoula. 2011. Mitigation and politeness in Greek invitation refusals: Effects of length of residence in the target community and intensity of interaction on non-native speakers' performance. Journal of Pragmatics 43. 1718-1740.

Bella, Spyridoula. 2014. Developing the ability to refuse: A cross-sectional study of Greek EFL refusals. Journal of Pragmatics 61. 35-62.

Bond, Michael Harris. 1991. Beyond the Chinese face: Insights from psychology. Hong Kong, Oxford \& New York: Oxford University Press.

Bond, Michael Harris \& Hwang Kwang-Kuo. 1986. The social psychology of Chinese people. In Michael Harris Bond (ed.), The psychology of the Chinese people, 213-266. Oxford: Oxford University Press. 
Brown, Penelope \& Stephen Levinson. 1987. Politeness: Some universals in language usage. Cambridge: Cambridge University Press.

Chang, Yuh Fang. 2009. How to say no: An analysis of cross-cultural difference and pragmatic transfer. Language Sciences 30. 477-493.

Chang, Yuh Fang. 2011. Refusing in a foreign language: An investigation of problems encountered by Chinese learners of English. Multilingual 30. 71-98.

Chen, Xing, Lei Ye \& Yanyin Zhang. 1995. Refusing in Chinese. In Gabriele Kasper (ed.), Pragmatics of Chinese as native and target language, 119-163. Manoa: University of Hawai'i Press.

Economidou-Kogetsidis, Maria. 2011. "Please answer me as soon as possible”: Pragmatic failure in non-native speakers' email requests to faculty. Journal of Pragmatics 43. 3193-3215.

Ellis, Rod. 1992. Learning to communicate in the classroom: A study of two language learners' requests. Studies in Second Language Acquisition 14. 1-23.

Félix-Brasdefer, J. César. 2006. Linguistic politeness in Mexico: Refusal strategies among male speakers of Mexican Spanish. Journal of Pragmatics 38. 2158-2187.

Fukushima, Saeko. 1996. Request strategies in British English and Japanese. Language Sciences 18. 671-688.

Gao, Ge \& Stella Ting-Toomey. 1998. Communicating effectively with the Chinese. Thousand Oaks, CA \& London: Sage.

Gu, Yueguo. 1990. Politeness phenomena in modern China. Journal of Pragmatics 14. 237-257.

Guo, Yin Ling. 2012. Chinese and American refusal strategy: A cross-cultural approach. Theory and Practice in Language Studies 2. 247-256.

Hassall, Tim. 2003. Requests by Australian learners of Indonesian. Journal of Pragmatics 35. 1903-1928.

Ho, David Y. F. 1986. Chinese patterns of socialization: A critical review. In Michael Harris Bond (ed.), The psychology of the Chinese people, 1-37. Hong Kong, Oxford \& New York: Oxford University Press.

Hofstede, Geert. 2001. Culture's consequences: Comparing values, behaviors, institutions, and organizations across nations. Thousand Oaks, CA: Sage.

Hong, Wei. 2011. Refusals in Chinese: How do L1 and L2 differ? Foreign Language Annals 44. 122-136.

Lee, Cynthia. 2004. Written requests in emails sent by adult Chinese learners of English. Language, Culture and Curriculum 4. 58-72.

Lee, Cynthia. 2005. A cross-linguistic study on Cantonese and English requests. Pragmatics 15. 395-422.

Lee, Cynthia. 2011. Strategy and linguistic preference of requests by Cantonese learners of English: An interlanguage and cross-cultural comparison. Multilingua 30. 99-129.

Lee, Cynthia. 2012. Mum, sister hit me: Interlanguage complaint strategies of Cantonese learners of English from childhood to their teens. International Review of Pragmatics 4. 80-111.

Lee-Wong, Song Mei. 2000. Politeness and face in Chinese culture. Frankfurt \& Berlin: Peter Lang.

Li, Honglin. 2007. A comparative study of refusal speech acts in Chinese and American English. Canadian Social Science 3. 64-67.

Li, Wei \& Yue Li. 1996. "My stupid wife and ugly daughter”: The use of pejorative references as a politeness strategy by Chinese speakers. Journal of Asian Pacific Communication 7. 129-141. 
Liao, Chao Chih \& Mary I. Bresnahan. 1996. A contrastive pragmatic study on American English and Mandarin refusal strategies. Language Sciences 18. 703-727.

Mills, Sara \& Dániel Z. Kádár. 2011. Politeness and culture. In Dániel Z. Kádár \& Sara Mills (eds.), Politeness in East Asia21-44. Cambridge \& New York: Cambridge University Press.

Pan, Yuling. 2000. Politeness in Chinese face-to-face interaction. Stamford, CT: Ablex.

Ren, Wei. 2012. Pragmatic development in Chinese speakers' L2 English refusals. EUROSLA Yearbook 12. 63-87.

Rinnert, Carol \& Hiroe Kobayashi. 1999. Requestive hints in Japanese and English. Journal of Pragmatics 31. 1173-1201.

Rose, Kenneth R. 2000. An exploratory cross-sectional study of interlanguage pragmatic development. Studies in Second Language Acquisition 22. 27-67.

Rose, Kenneth R. 2009. Interlanguage pragmatic development in Hong Kong, phase 2. Journal of Pragmatics 41. 2345-2364.

Sadeghi, Karim \& Senam Savojbolaghchilar. 2011. A comparative study of refusal strategies used by Iranians and Americans. International Journal of Academic Research 3. 601-606.

Satter, Hiba Qusay Abdul, Salasiah Che Lah \& Raja Rozina Rja Suleiman. 2011. Refusal strategies in English by Malay university students. GEMA Online 11. 69-81.

Scollon, Ron \& Suzanne B. K. Scollon. 1991. Topic confusion in English-Asian discourse. World Englishes 10. 113-125.

Snow, Donald B. 2004. Cantonese as written language: The growth of a written Chinese vernacular. Hong Kong: Hong Kong University Press.

Wang, Aihua. 2001. Refusal realization patterns in English and Chinese. Foreign Language Teaching and Research 33. 178-185.

Yang, Jia. 2008. How to say "no" in Chinese: A pragmatic study of refusal strategies in five TV series. In Marjorie K. M. Chan \& Hana Kang (eds.), Proceedings of the 20th North American Conference on Chinese Linguistics (NACCL-20), 1041-1058. Columbus: Ohio State University.

\section{Bionote}

\section{Cynthia Lee}

Cynthia Lee is Associate Professor at the Centre for Applied English Studies, the University of Hong Kong. She teaches undergraduate and postgraduate courses and supervises PhD students. She has conducted research projects related to L2 pragmatics and language education. Her research interests include interlanguage pragmatic development, tutor-tutee discourse and learning in L2 writing consultations, automated feedback on L2 writing, and second-language acquisition and pedagogy. Her research articles have appeared in internationally refereed journals and books. 